COMUNICACIÓN CORTA

\title{
Aislamiento de Salmonella spp. a partir de huevos de gallina para consumo comercializados en la ciudad de Casilda, Santa Fe, Argentina
}

\author{
Freije $\mathrm{JA}^{1}$, Comba $\mathrm{ER}^{1}$, Caffer $\mathrm{MI}^{2}$, Alcain $\mathrm{AC}^{2}$, Pidone $\mathrm{CL}^{1^{*}}$ \\ ${ }^{1}$ Facultad de Ciencias Veterinarias, Universidad Nacional de Rosario, Argentina. \\ 2 Servicio de Enterobacterias Instituto Nacional de Enfermedades Infecciosas - A.N.L.I.S. "Dr. Carlos \\ G. Malbrán".
}

\author{
* Correspondencia: FCV-UNR, Av. Ovidio Lagos y Ruta 33 (2170) Casilda, Santa \\ Fe, Argentina. \\ E-mail: cpidone@fveter.unr.edu.ar
}

Recibido: 7 Diciembre 2018. Aceptado: 6 Junio 2019. Disponible en línea: 7 Junio 2019

Editor: L. Frizzo

RESUMEN. Con el objetivo de determinar la presencia de Salmonella spp. en huevos destinados al consumo humano en la ciudad de Casilda, Santa Fe, Argentina, se recolectaron 125 huevos de gallina obtenidos en comercios de la ciudad y se muestrearon yemas y cáscaras. Ambas muestras se sembraron en caldo tetrationato con el agregado de solución de yodo y verde brillante y se incubaron a 43ㅇ C durante 24 horas. De cada medio sembrado se tomó una alícuota de la superficie y se sembró en agar Xilosa-Lisina-Desoxicolato, incubándose durante $24-48$ horas a $37^{\circ} \mathrm{C}$. Las colonias desarrolladas se identificaron utilizando pruebas bioquímicas y aquellas identificadas como Salmonella spp. se serotipificaron. Se aislaron 3 cepas de Salmonella spp: Salmonella ser. Tiphymurium y Salmonella ser. Anatum a partir de muestras de yema y Salmonella ser. Anatum a partir de la cáscara de un tercer huevo. El aislamiento de Salmonella spp. en huevos para consumo humano refuerza la necesidad de tomar medidas de bioseguridad para reducir la incidencia de esta bacteria en las granjas.

SUMMARY. Isolation of Salmonella spp. from hen eggs in Casilda city, Santa Fe, Argentina. In order to determine the presence of Salmonella spp. in eggs from Casilda city, Santa Fe, Argentina, a total of 125 eggs were collected from different stores and yolks and egg shells were sampled. Both samples were seeded in tetrathionate broth with the addition of iodine and brilliant green solution and incubated at $43{ }^{\circ} \mathrm{C}$ for 24 hours. An aliquot of the surface was taken from each medium seeded and seeded on Xylose-LysineDeoxycholate agar, being incubated for $24-48$ hours at $37^{\circ} \mathrm{C}$. The developed colonies were identified using biochemical tests and those identified as Salmonella spp. they were serotyped. Three strains of Salmonella spp. were isolated: Salmonella ser. Tiphymurium and Salmonella ser. Anatum from samples of yolk and Salmonella ser. Anatum from the egg shell of a third egg. The isolation of Salmonella spp. in eggs for human consumption reinforces the need to take biosecurity measures to reduce the incidence of this bacterium in the farms.

Palabras clave: huevos, Salmonella, Argentina

Keywords: eggs, Salmonella, Argentina

\section{Introducción}

Los reportes sobre la incidencia de gastroenteritis causadas por Salmonella spp. en seres humanos han aumentado en diferentes partes del mundo. Las fuentes de infección, a menudo, se han asociado al consumo de alimentos de origen animal y sus subproductos, en especial de huevos crudos o parcialmente cocidos, como así también de vegetales y de aguas contaminadas (De Franceschi et al., 1998; Leyva Castillo et al., 1996). Son frecuentes los casos producidos por esta bacteria, muchas veces en forma de brotes epidémicos (EFSA, 2011).

Por otra parte, los huevos de gallina recién puestos no suelen estar contaminados, si bien algunos microorganismos pueden llegar a él a través del oviducto. Los microorganismos presentes en el interior del huevo provienen principalmente del tracto intestinal de las aves, el polvo o las cajas de embalaje y almacenamiento y penetran a través de los poros de la cáscara si ésta se encuentra caliente y se contamina con materia fecal 
fría: entonces los gérmenes pasan al interior conforme ésta se va enfriando (Leyva Castillo et al., 1996).

Los datos publicados relativos a la incidencia de huevos contaminados con Salmonella spp. en nuestro país y en el mundo son muy variables (De Franceschi et al., 1998; Mancera Martínez et al., 2005), no habiendo registros de este tipo en la ciudad de Casilda. Por ello, el objetivo de este trabajo fue determinar la presencia de Salmonella spp. en huevos destinados al consumo humano en la ciudad de Casilda, Santa Fe, lo cual podría representar un riesgo para la salud pública.

\section{Materiales y métodos}

Durante el período comprendido entre el 1 de noviembre de 2011 y el 30 de julio de 2012 se recolectaron 125 huevos de gallina obtenidos en comercios $u$ otros puestos de venta ubicados en diferentes zonas de la ciudad de Casilda, provincia de Santa Fe, Argentina, sin considerar el origen de los mismos, la fecha de postura ni la forma de almacenamiento. Para determinar la muestra se separó a la ciudad en bloques y dentro de cada bloque se hizo un muestreo simple al azar de puestos de venta, de donde se tomaron 6 huevos de cada uno. El tamaño muestral se estableció de acuerdo a la fórmula siguiente: $n=\left(Z_{\alpha}^{2} * p * q\right) / E^{2}$, en donde $Z_{\alpha}$ es el nivel de confianza y $\mathrm{E}$ el error máximo admisible en términos de proporción. Por lo tanto, con una confianza del $95 \%$ y en $\mathrm{E}=0,03$ se obtuvo $n=$ $\frac{1.96^{2} * 0,03 * 0,97}{0.03^{2}}=124.21 \cong 125$.

Las muestras de cáscara se tomaron con tijera estéril, realizando un corte de $1 \mathrm{~cm}^{2}$. Las muestras de yema se obtuvieron utilizando hisopos de dacrón estériles. Ambos tipos de muestras se sembraron, independientemente, en tubos que contenían $10 \mathrm{ml}$ de caldo tetrationato (Laboratorio Britania SA, CABA, Argentina) con el agregado de solución de yodo y verde brillante (caldo de Muller - Kauffmann) y se incubaron a 43으 C en baño maría durante 24 horas. Posteriormente, con un ansa de siembra se tomó una alícuota de la superficie de cada uno de los tubos y se sembró en agar XilosaLisina-Desoxicolato (XLD. Biokar Diagnostics, Francia), incubándose durante $24-48$ horas a $37{ }^{\circ} \mathrm{C}$ (Bridson, 2006). Las colonias sospechosas de ser Salmonella spp. (rojas con centro negro) se identificaron utilizando pruebas bioquímicas convencionales: Agar-hierro-triple azúcar (Agar TSI), pruebas IMViC (Indol, Rojo de metilo, Voges-Proskauer y Citrato), prueba de la ONPG (Orto Nitro Fenil Galactopiranósido) y prueba de la ureasa. La confirmación y posterior sero-tipificación de las cepas se realizó de acuerdo con el Esquema de White - Kauffmann - Le Minor (Caffer et al., 2001), en el Servicio Enterobacterias, del Instituto Nacional de Enfermedades Infecciosas - A.N.L.I.S. " Dr. Carlos G. Malbrán".

\section{Resultados y discusión}

En total se aislaron 3 cepas de Salmonella a partir de 3 huevos diferentes y provenientes de diferentes tandas ( $2,4 \%$ de los huevos analizados). A partir de la yema de un huevo se aisló Salmonella ser. Typhimurium y a partir de otro se aisló Salmonella ser. Anatum. Por otro lado, también se recuperó Salmonella ser. Anatum a partir de la cáscara de un tercer huevo.

Se considera al consumo de huevo contaminado como una de las vías de infección con Salmonella spp. para el hombre (Bueno et al., 2017; EFSA, 2011; Eng et al., 2015). En un estudio previo en el que se analizaron 400 huevos de la ciudad de México, se aisló solo una cepa de Salmonella ser. Enteritidis a partir de un huevo contaminado, lo cual significa un 0,25\% de las muestras (Mancera Martínez et al., 2005). Leyva Castillo y col. (1996) analizaron huevos de gallina frescos para consumo humano y de las 330 muestras de cáscara de huevo solamente de $2(0,6 \%)$ se recuperó Salmonella, mientras que no se aisló esta bacteria en ninguna de las 180 muestras de clara y yema. Estos autores también citan un trabajo de De la Osa y col. en donde se obtuvo $1 \%$ de positividad a Salmonella en cáscara de huevo, pero sin que se aislase del contenido; y otro de Perales y col., que estudiaron 180 muestras de huevos no involucrados en brotes de enfermedades de transmisión alimentaria (ETA) y procedentes de granja o de almacenes, en donde aislaron Salmonella en el interior del huevo de una de las muestras $(0,6 \%)$ y en $5(2,8 \%)$ de las cáscaras (Leyva Castillo et al., 1996).

En nuestro estudio, que no utilizó pre-enriquecimiento (lo que podría haber incrementado el número de muestras positivas), a partir de yema de huevo se aislaron 2 serovariedades que ya han sido descriptas como patógenos responsables de ETA en humanos (Krause et al., 2001; Leyva Castillo et al., 1996; Noseda et al., 2002). Por otro lado, en el caso del aislamiento de Salmonella a partir de la cáscara, su ausencia en la yema hace pensar que la integridad de la cáscara y de la cutícula pudo haber evitado la penetración de la bacteria al interior del huevo. A diferencia del serotipo específico de las aves (S. ser. Gallinarum), las restantes salmonelas pueden afectar a un amplio rango de hospedadores, lo que complica la aplicación de programas de control. A esto se le suma el hecho de que estas serovariedades suelen cursar de manera subclínica en las explotaciones avícolas, lo que dificulta su detección (Leyva Castillo et al., 1996).

El aislamiento de 3 cepas de Salmonella spp., que pueden ser causa de ETA en humanos, a partir de huevos destinados al consumo humano en la ciudad de Casilda, refuerza la necesidad del cocimiento del producto antes de su consumo, la conservación de los huevos bajo condiciones adecuadas, el consumo antes de la fecha recomendada y la importancia de tomar medidas básicas de bioseguridad para disminuir la incidencia de esta bacteria en las granjas avícolas. En el 
futuro sería importante poder comparar estas cepas con otras aisladas con anterioridad.

\section{Bibliografía}

Bridson EY. 2006. The Oxoid Manual. 9th Edition. Basingstoke (Inglaterra), Oxoid Limited. Disponible en: https://vdocuments.site/oxoid-manual-9th-edition.html.

Bueno DJ, Soria MC, Soria MA, Procura F, Rodriguez FI, Godano El. 2017. Egg Production Systems and Salmonella in South America. En: Producing Safe Eggs. Microbial Ecology of Salmonella. Elsevier B.V. Chapter 6: 87-110.

Caffer MI, Terragno R. 2001. Manual de procedimientos para la caracterización de Salmonella. Instituto Nacional de Enfermedades Infecciosas - Ministerio de Salud, Buenos Aires. $37 p p$.

De Franceschi M, Viora S, Anselmo R, Barrios H. 1998. Salmonella enteritidis en huevos frescos. Rev. Med. Vet. (Buenos Aires) 79: 5-7.

EFSA. 2011. Scientific Report of EFSA and ECDC. The European Union Summary Report on Trends and Sources of Zoonoses, Zoonotic Agents and Food-borne Outbreaks in 2009. EFSA Journal 9: 2090

Eng SK, Pusparajah P, Ab Mutalib NS, Ser HL, Chan KG, Lee LH. 2015. Salmonella: A review on pathogenesis, epidemiology and antibiotic resistance. Front. Life Sci. 8: 284-293.

Krause G, Terzagian R, Hammond R. 2001. Outbreak of Salmonella serotype anatum infection associated with unpasteurized orange juice. South Med. J. 94: 1168-1172.

Leyva Castillo V, Valdés Amey E, Cisneros Despaigne E, Pérez Rodríguez O. 1996. Determinación de Salmonella y enterobacterias totales en huevos frescos de gallina. Rev. Cubana Aliment. Nutr. 10: 83-86.

Mancera Martínez A, Vázquez Navarrete J, Ontiveros Corpus ML, Duran Valencia S, Lopez Huidobro D, Tenorio Gutiérrez V. 2005. Identificación de Salmonella Enteritidis en huevo para consumo en la ciudad de México. Tec. Pecu. Mex. 43: 229-237.

Noseda RP, Bigalli MC, Andrich MG, Cordeviola JM. Bardón JC, Martínez AH, Combessies GM. 2002. Aislamiento de Salmonella en muestras clínicas humanas, animales $\mathrm{y}$ alimentos, durante 1988-2001. Vet. Arg. 19: 752-59. 